but also equally to provide the knowledge on which we must base any sound practice for the most effective utilisation of coal, it is essential to undertake a far more fundamental study of this mineral, and in particular to investigate separately the many components of the coal aggregate.

\section{The Species Problem}

$\mathrm{M}^{\mathrm{A}}$ AINLY from a study of the water-beetles, Prof. F. Balfour-Browne has come to some conclusions as to the origin of species by means of natural selection which he brings forward in his presidential address to Section D (Zoology). $\mathrm{He}$ points out that, although a struggle for existence undoubtedly occurs, choice also plays a part in the formation of different communities of water-beetles associated with different types of habitat, and that even localisation under particular climatic conditions is probably partly due to choice.

Choice of a particular food-plant by certain individuals of a species may give rise to biological races, such as are known to exist in Nature and can be produced artificially, and such races may be one source of origin of new species. In any group, species are variously related, some being very distinct while others form clusters and are difficult to distinguish. The clustered species are not usually members of the same community and may perhaps be accounted for on the assumption that they originated as biological races. As to these clusters, there seems to be no evidence that the distinctive characters are hereditary, and it seems possible that they are merely due to the effect of environment upon each succeeding generation.

The majority of the species-characters by which the water-beetles are separated are non-vital and cannot therefore have evolved through the action of natural selection. In some cases the structure is common to other groups but the function is different. The clubbed antennæ found in Hydrophilidæ have appeared several times in the Coleoptera, but if they had been wiped out in all these other groups before the Hydrophilidæ were first studied, we should doubtless be describing them as specially evolved in connexion with respiration in these beetles.

Among these species-characters it is possible to trace what might be called stages in their evolution running through whole groups or families, suggesting that, just as growth is a definite property of the organism, so evolution is an inherent property of the species. But the discoveries in connexion with chromosome control of characters suggest that possibly what has been described as orthogenesis may be the result of mutations caused by external stimuli or, if function can produce an alteration of structure, physiological activities may produce these lines of evolution on the assumption, still requiring proof, that acquired characters are inherited. The inheritance of acquired characters must also depend upon the ultimate effect of changes of habit, physiological activity and structure upon the germ-cell chromosomes, so that the real struggle for existence seems to be in these latter, the first function of which is to see that like produces like, while external influences are perpetually endeavouring to prevent them carrying out their duty.

\section{Polar Research}

TN his presidential address to Section E (Geo1 graphy) Prof. F. Debenham discusses "Some Aspects of the Polar Regions". In spite of an extensive literature on the exploration of the polar regions, there are few sources for a general appreciation of their value to man. The economic aspect is perhaps the best known, since most expeditions of the past have been prompted to some extent by hopes of making discoveries which would ultimately return a profit. Several of the earlier resources, however, were speedily exhausted by the spirit of competition which ruled amongst the different nations. The disappearance of the arctic whale and the reduction in numbers of the fur seal are two instances of this.

Among the potential values that yet remain to be exploited in the polar regions, there is the prospect of using them for air routes. Prof. Debenham urges caution as to acceptance of the exaggerated accounts of possible mineral wealth, especially in the Antarctic. Although by analogy with other parts of the world there are doubtless valuable deposits of precious metals, the almost universal covering of ice prevents prospecting and would hinder mining operations.

The economic aspects of the lands in high latitudes naturally lead to the subject of the national ownership of polar lands and the unusual conditions in which claims have to be made. In the Antarctic, in particular, there can be no occupation, and it seems that its place as a reason for territorial rights will have to be taken by exploration and investigation.

The polar regions are of interest as a field for adventure, and also, in the more accessible parts, as a resort for holidays. So far as Europe is concerned, however, the field is narrowed down to little more of the Arctic than the Svalbard (Spitsbergen) group of islands. Associated with this aspect is another which may yet prove to be of greater value than any other. The polar regions 